\title{
Target-site and non-target-site based resistance to the herbicide tribenuron- methyl in flixweed (Descurainia sophia L.)
}

\author{
Qian Yang ${ }^{1}$, Wei Deng ${ }^{1}$, Xuefeng $\mathrm{Li}^{1}$, Qin Yu², Lianyang Bai ${ }^{3}$ and Mingqi Zheng ${ }^{1 *}$
}

\begin{abstract}
Background: Flixweed (Descurainia sophia L.) is a troublesome and widespread broadleaf weed in winter fields in China, and has evolved high level resistance to acetolactate synthase (ALS)-inhibiting sulfonylurea herbicide tribenuron-methyl.

Results: We identified a resistant flixweed population (N11) exhibiting 116.3-fold resistance to tribenuron-methyl relative to the susceptible population (SD8). Target-site ALS gene mutation Pro-197-Thr was identified in resistant plants. Moreover, the resistance can be reversed to 28.7-fold by the cytochrome P450 inhibitor malathion. The RNASequencing was employed to identify candidate genes involved in non-target-site metabolic resistance in this population. Total 26 differentially expressed contigs were identified and eight of them (four P450s, one ABC transporter, three glycosyltransferase) verified by qRT-PCR. Consistent over-expression of the two contigs homology to CYP96A13 and ABCC1 transporter, respectively, were further qRT-PCR validated using additional plants from the resistant and susceptible populations.

Conclusions: Tribenuron-methyl resistance in flixweed is controlled by target-site ALS mutation and non-target-site based mechanisms. Two genes, CYP96A13 and ABCC1 transporter, could play an important role in metabolic resistance to tribenuron-methyl in the resistant flixweed population and justify further functional studies.
\end{abstract}

Keywords: Acetolactate synthase, Cytochrome P450, Flixweed, Tribenuron-methyl, Target-site based resistance, Nontarget-site based resistance, Metabolic resistance, RNA-Seq

\section{Background}

Herbicide resistance is the consequence of weed evolutionary adaptation to herbicide selection, and can be classified to target-site based resistance (TSR) and non-target-site based resistance (NTSR). TSR is widely reported in resistant weed species, which is endowed by gene mutations in target enzymes, such as acetolactate synthase (ALS)-, acetyl-CoA carboxylase (ACCase)-, protoporphyrinogen IX oxidase (PPO)-, 4hydroxyphenylpyruvate dioxygenase (HPPD)-, and 5enolpyruvylshikimate-3-phosphate synthase (EPSPS) [1-6]. To date, twenty-eight amino acid substitutions (numbers of amino acid in parentheses) in ALS endowing ALS herbicides resistance were identified at

\footnotetext{
* Correspondence: mqzheng@cau.edu.cn

${ }^{1}$ Department of Applied Chemistry, College of Science, China Agricultural

University, Beijing 100193, China

Full list of author information is available at the end of the article
}

sites of Ala122 (3), Pro197 (13), Ala205 (2), Asp 376(1), Arg377 (1), Trp574 (3), Ser653 (3) and Gly654 (2) in weed species [5-7]. Non-target-site resistance is achieved by mechanisms reducing herbicide concentration reaching the target-site $[1,8]$. One of the important NTSR mechanisms is the enhanced rates of herbicide metabolism (here in after referred to as metabolic resistance) often involving cytochrome P450 monooxygenase (thereafter referred to as $\mathrm{P} 450), \mathrm{ABC}$ transporter, glutathione $\mathrm{S}$-transferase (GST), glycosyltransferase (GT) and peroxidase (POD) [9-12]. Compared to TSR, NTSR is less investigated (especially in broadleaf weed species) and remains poorly understood due to its complexity and diversity. NTSR may cause weeds evolve unpredictable resistance to diverse herbicides of different modes of action, even including herbicides not yet marketed $[12,13]$. In addition, the resistance management strategies of herbicide mixtures and rotations, which are effective to manage TSR, may 
have little or no effects on NTSR metabolic resistance [12]. Therefore, NTSR threatens not only weed management, but also the utility of new herbicides.

Flixweed (Descurainia sophia L.) is a self-pollinated annual and notorious weed widely distributed in winter wheat cropping regions in China. Effective control of this weed heavily relied on the ALS-inhibiting herbicide (hereafter referred to as ALS herbicide) tribenuronmethyl, which targeted at ALS enzymes. Inhibition of ALS enzyme will affect synthesis of the branched-chain amino acids (Val, Leu and Ile) and eventually result in the death of plants. In addition, tribenuron-methyl can be absorbed by roots, stems, leaves, and transfer in weeds. Flixweed populations across the country have evolved high level resistance to tribenuron-methyl, and ALS gene mutation at Pro197 or Asp376 was found to decrease the enzyme sensitivity, which is mainly responsible for resistance to tribenuron-methyl in flixweed [14-19]. However, NTSR mechanisms endowing tribenuron-methyl-resistance in flixweed have not previously investigated.

RNA-Sequencing (RNA-Seq) has been recently used in transcriptome analysis of plant response to herbicide stresses in grass weeds Eleusine indica [20] and Echinochloa cruss-galli [21], and in identifying genes involved in NTSR in Lolium rigidum [22, 23] and Alopecurus myosuroides [24]. In the current study, a flixweed population with both TSR and NTSR mechanisms to tribenuron-methyl was identified. In particular, RNA transcriptome sequencing was conducted to identify genes involved in NTSR to tribenuron-methyl in this population. Two genes, CYP96A13 and ABCC1 transporter were deduced to play an important role in metabolic resistance to tribenuron-methyl in the resistant flixweed population. This is the first transcriptome-wide study in identifying NTSR genes in a broadleaf weed species.

\section{Results}

To disclose the TSR and NTSR mechanisms to tribenuron-methyl, an R flixweed population $\mathrm{N} 11$ and an S population SD8 were used in this study. Tribenuronmethyl dose response, in vitro ALS activity and ALS gene sequencing were conducted to identify the TSR mechanism. The RNA-Seq was employed to identify candidate genes involved in NTSR in R population.

\section{Tribenuron-methyl dose response in the absence and presence of malathion}

Whole-plant response experiments demonstrated that the R (N11) population has evolved a high level (116.3fold) resistance to tribenuron-methly (Table 1). More importantly, the P450 inhibitor malathion can partially reverse the resistance (Fig. 1 and Table 1). Malathion
Table $1 \mathrm{GR}_{50}$ and $\mathrm{I}_{50}$ values of the susceptible (SD8) and resistant (N11) flixweed populations to tribenuron-methyl, in the absence and presence of cytochrome P450 inhibitor malathion

\begin{tabular}{lllllllll}
\hline Herbicides & $\mathrm{SD} 8(\mathrm{~S})$ & & $\mathrm{N} 11(\mathrm{R})$ & & \\
\cline { 2 - 3 } \cline { 5 - 7 } & $\mathrm{GR}_{50}{ }^{\mathrm{a}}$ & $\mathrm{I}_{50}{ }^{\mathrm{b}}$ & & $\mathrm{GR}_{50}{ }^{\mathrm{a}}$ & $\mathrm{RF}^{\mathrm{c}}$ & $\mathrm{I}_{50}{ }^{\mathrm{b}}$ & $\mathrm{RF}^{\mathrm{c}}$ \\
\hline Tribenuron-methyl & $0.046 \mathrm{a}$ & $1.77 \mathrm{a}$ & & $5.35 \mathrm{~b}$ & 116.3 & $54.65 \mathrm{~b}$ & 30.9 \\
$\begin{array}{l}\text { Tribenuron-methyl }+ \\
\text { malathion }\end{array}$ & $0.039 \mathrm{a}$ & - & & $1.12 \mathrm{C}$ & 28.7 & - & - \\
& & & & & &
\end{tabular}

Resistance levels were indicated by the resistance factor (RF). $G R_{50}$ or $I_{50}$ values with different letters are significantly different at $P=0.05$ significant level. Data were means of two experiments

${ }^{a} \mathrm{GR}_{50}$, herbicide rate causing $50 \%$ growth reduction of plants

${ }^{\mathrm{b}} \mathrm{I}_{50}$, herbicide concentration causing $50 \%$ inhibition of the ALS activity

${ }^{c} \mathrm{RF}$ (resistance factor) $=\mathrm{GR}_{50}$ or $\mathrm{I}_{50}(\mathrm{R}) / \mathrm{GR}_{50}$ or $\mathrm{I}_{50}(\mathrm{~S})$

alone at $720 \mathrm{~g}$ a.i. $\mathrm{ha}^{-1}$ had no visual effect on the growth of $\mathrm{R}$ and $\mathrm{S}$ plants. However, malathion greatly (4-fold) reduced the resistance level of the R (N11) population when used prior to tribenuron-methyl treatment. In contrast, malathion almost had no effects on the susceptibility of the S (SD8) population to tribenuron-methyl (Fig. 1 and Table 1). The P450 inhibitor malathion has long been used as a indicator of P450 involvement in metabolic resistance to ALS herbicides [25]. The results indicate that one or more P450s may mediate resistance to tribenuron-methyl in the $\mathrm{R}$ flixweed population.

\section{ALS activity assays in vitro}

The ALS in vitro assay showed that ALS enzyme extracted from R (N11) plants was 30.9-fold resistant to tribenuron-methyl compared to that from S (SD8) plants (Table 1 and Fig. 2). The reduced sensitivity of ALS enzyme in R plants is likely due to mutation(s) in ALS gene.

\section{ALS gene sequencing}

Two ALS genes with full lengths of $1998 \mathrm{bp}$ and 2004 bp, respectively was cloned from S (SD8) and R (N11) plants. These two ALS genes displayed more than $95 \%$ homology with the known ALS genes in flixweed (EMBL/Genbank accession JQ868736, JQ868737, JQ868738). A Pro-197-Thr substitution known to endow ALS herbicide resistance was identified in the 1998 bp ALS from $\mathrm{R}$ but not $\mathrm{S}$ plants. No amino acid substitutions were found in 2004 bp ALS from both R and S plants. It is clear that target-site ALS Pro-197-Thr mutation is in part responsible for tribenuron-methyl resistance in the $R$ population.

\section{Transcriptome sequencing and assembly}

RNA-Seq was conducted to identify genes involved in NTSR mechanism in resistant flixweed population. Total $33.36 \mathrm{~Gb}$ data with $272,121,520$ raw reads were generated from the four libraries. After removing reads 


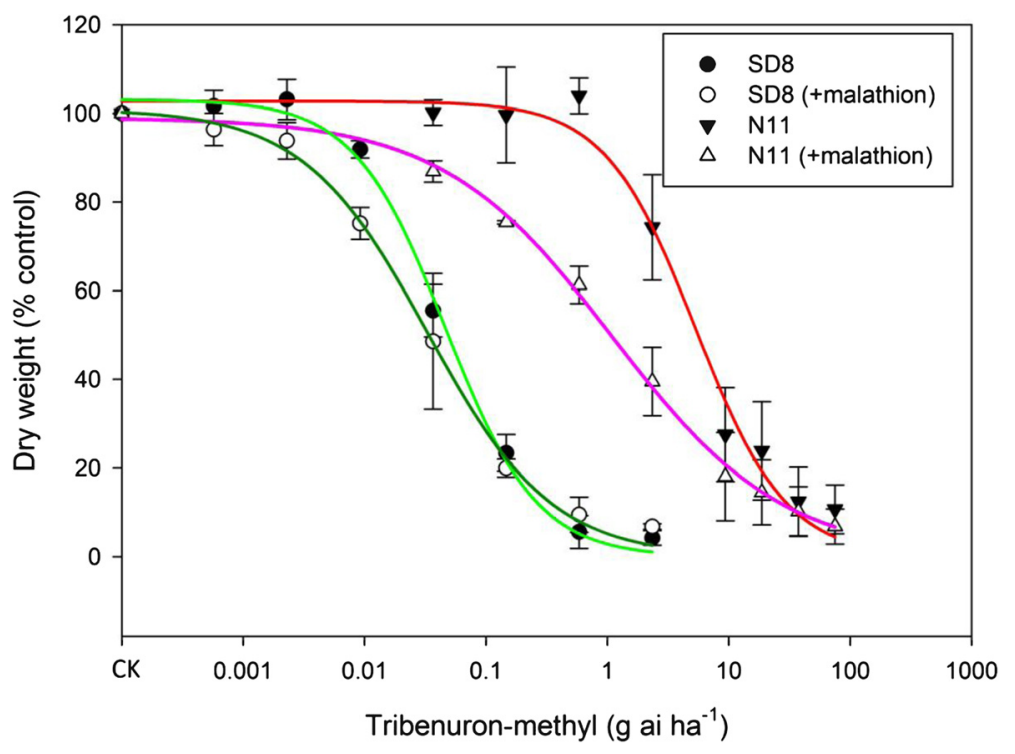

Fig. 1 Dose-response curves of susceptible (SD8) and resistant (N11) flixweed populations to tribenuron-methyl in the absence and presence of cytochrome P450 inhibitor malathion. Each data point is the mean \pm SE of two experiments

containing adaptor or ploy- $\mathrm{N}$ and low quality reads, there were $266,750,156$ clean reads ranging from $31,286,811$ to $36,457,368$ per sample that were used for assembly (Additional file 1). Clean reads were assembled to 84,085 transcripts in the range of 201 to $15,697 \mathrm{bp}$. Among these transcripts, 52,898 unigenes $>200 \mathrm{bp}$, and 23,072 unigenes $>500 \mathrm{bp}$, with a mean length of $839 \mathrm{bp}$ and an N50 length of 1,569 bp were obtained using the longest transcript in each loci of each gene (Table 2, Additional file 2).

\section{Gene functional annotation and classification}

Unigene annotation was performed by blast-searching against seven public databases. There were 35,211 $(66.56 \%)$ unigenes successfully annotated in at least one of NCBI non-redundant protein sequences database $(\mathrm{Nr}), \mathrm{NCBI}$ non-redundant nucleotide sequences database (Nt), Pfam (Protein family), KOG/COG (Clusters of Orthologous Groups of proteins), Swiss-port, Kyoto Encyclopedia of Genes and Genomes (KEGG) and Gene ontology (GO) databases, with 5,118 (9.67 \%) unigenes

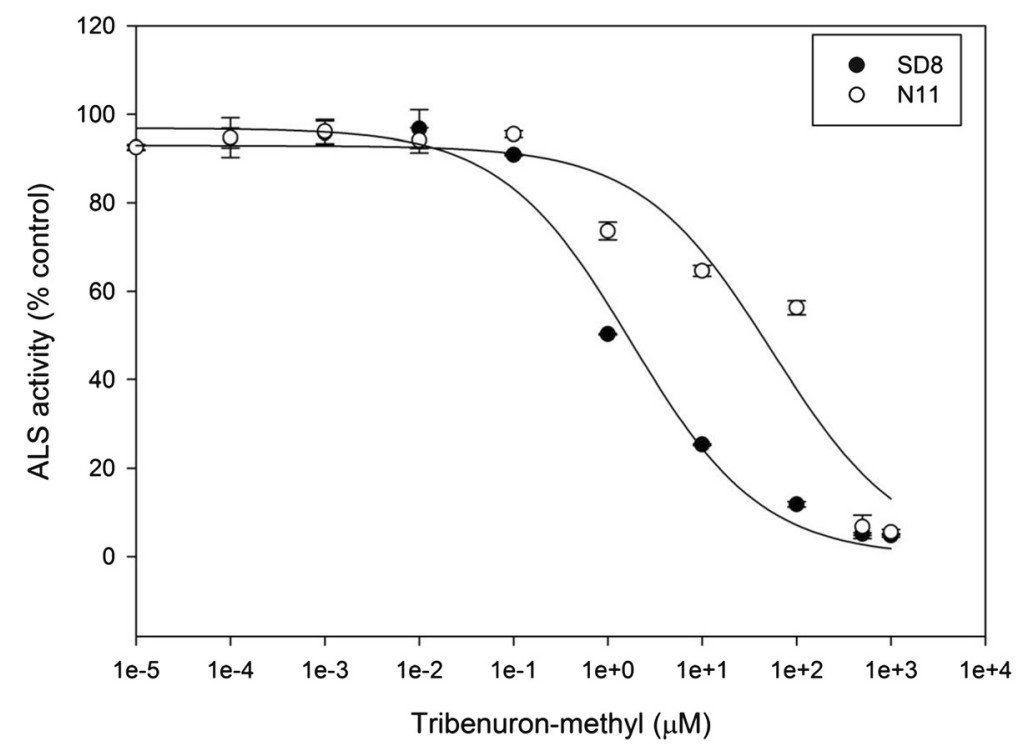

Fig. 2 Effect of tribenuron-methyl on ALS activity of susceptible (SD8) and resistant (N11) flixweed populations. Each data point is the mean \pm SE of two experiments 
Table 2 Summary of assembly quality for flixweed RNA-seq

\begin{tabular}{ll}
\hline Assembly quality parameters & \\
\hline Total raw reads & $272,121,520$ \\
Total clean reads & $266,750,156$ \\
Clean bases & $33.36 \mathrm{G}$ \\
Transcripts generated & 84,085 \\
No. unigenes > $200 \mathrm{bp}$ & 52,898 \\
No. unigenes > 500 bp & 23,072 \\
Maximum length & 15,697 \\
Minimum length & 201 \\
Average unigene length & 839 \\
N50 value & 1569 \\
N90 value &
\end{tabular}

${ }^{a} \mathrm{~N} 50,50 \%$ of the assembled bases were incorporated into sequences with length of $\mathrm{N} 50$ or longer

${ }^{b} \mathrm{~N} 90,90 \%$ of the assembled bases were incorporated into sequences with length of $\mathrm{N} 90$ or longer

in all seven databases (Table 3). This includes 28,446 unigenes (53.77\%) that had a hit in $\mathrm{Nr}$ database, 30,571 $(57.79 \%)$ in Nt database and 21,179 (40.03 \%) in SwissProt database. The results of $\mathrm{Nr}$ database annotation indicate that the $D$. sophia has sequence similarities to Arabidopsis lyrata (28.5\% of total unigenes), Arabidopsis thaliana (26.4\%), Capsella rubella (20.8\%), Eutrema salsugineum (10.0\%) and Brassica napus (4.8\%) (Additional file 3).

GO assignments were used to predict the functions of unigenes by classifying them into ontology of molecular function (MF), biological process (BP) and cellular component (CC). There are 21,670 unigenes in $\mathrm{R}$ and $\mathrm{S}$ samples that were divided into 56 functional subgroups based on the sequence homologies. The largest gene

Table 3 Gene annotation by BLAST-searching against public databases

\begin{tabular}{lll}
\hline Public database & $\begin{array}{l}\text { Number of } \\
\text { unigenes }\end{array}$ & Percentage (\%) \\
\hline Annotated in NR & 28,446 & 53.77 \\
Annotated in NT & 30,571 & 57.79 \\
Annotated in KEGG & 9002 & 17.01 \\
Annotated in SwissProt & 21,179 & 40.03 \\
Annotated in PFAM & 19,032 & 35.97 \\
Annotated in GO & 21,670 & 40.96 \\
Annotated in KOG & 10,231 & 19.34 \\
Annotated in all Databases & 5118 & 9.67 \\
Annotated in at least one Database & 35,211 & 66.56 \\
Total unigenes & 52,898 & 100 \\
\hline
\end{tabular}

subgroup in molecular function was binding $(13,027$ unigenes, $60.12 \%)$, followed by catalytic activity $(10,498$ unigenes, $48.44 \%)$ and transporter activity $(1,517$ unigenes, $7.00 \%)$. The largest gene subgroup in biological process was cellular process (13,126 unigenes, $60.57 \%)$, followed by metabolic process $(12,669$ unigenes, $58.46 \%)$ and single-organism process (10,626 unigenes, $49.04 \%)$. The largest gene subgroup in cellular component was cell (10,153 unigenes, $46.85 \%)$, followed by cell part (10,152 unigenes, $46.85 \%)$ and organelle (7,351 unigenes, $33.92 \%$ ) (Fig. 3).

KEGG is a platform for understanding functions and utilities of the gene products, especially large-scale molecular datasets generated by genome sequencing and other high-throughput experimental technologies. There are 9,002 unigenes that were classified into pathways of metabolism (4,536 unigenes, $50.39 \%$ ), genetic information processing (1,983 unigenes, $22.03 \%)$, organismal systems (1,502 unigenes, $16.69 \%)$, cellular processes (979 unigenes, $10.88 \%$ ) and environmental information processing (882 unigenes, $9.80 \%$ ) (Fig. 4) There are 883 unigenes that were annotated as NTSR-related genes including 258 P450s, 200 ABC transporters, 65 GSTs, 305 GTs and 55 PODs.

\section{Differential gene expression and functional enrichment analysis}

In order to identify the candidate genes involved in resistance to tribenuron-methyl, differential expression analysis was performed using the DEGSeq program [26]. Pearson correlation coefficients (Additional file 4) demonstrated that the gene expression models among different plants within or between the two flixweed populations have high similarity. In total, 902 of 52,898 unigenes were identified to be significantly differentially expressed (q-value $<0.05$ and $\mid \log _{2}$ (Fold change) $\mid>1$ ) in the $\mathrm{R}$ and $\mathrm{S}$ plants, including 536 up- and 366 downregulated in N11 (Additional file 5).

To further characterize the function of differentially expressed genes (DEGs), GO and KEGG enrichment analysis were conducted. In total, 574 DEGs were enriched in 2,323 GO terms, with 171 DEGs significantly enriched in 9 GO terms. We used up-regulated and down-regulated DEGs to perform GO enrichment analysis, respectively. Among the up-regulated genes, three GO terms including "response to UV-B" (7) and "response to UV" (8) in the category of BP; "transition metal ion binding" (63) in the category of MF were significantly enriched between R (N11) and S (SD8) samples (Additional file 6-A). Among the down-regulated genes, GO terms including "DNA integration" (9), "glycerol metabolic process" (5) and "alditol metabolic process" (5) in the category of BP; "ATPase activity, coupled to transmembrane movement of ions, phosphorylative 
Gene Function Classification (GO)

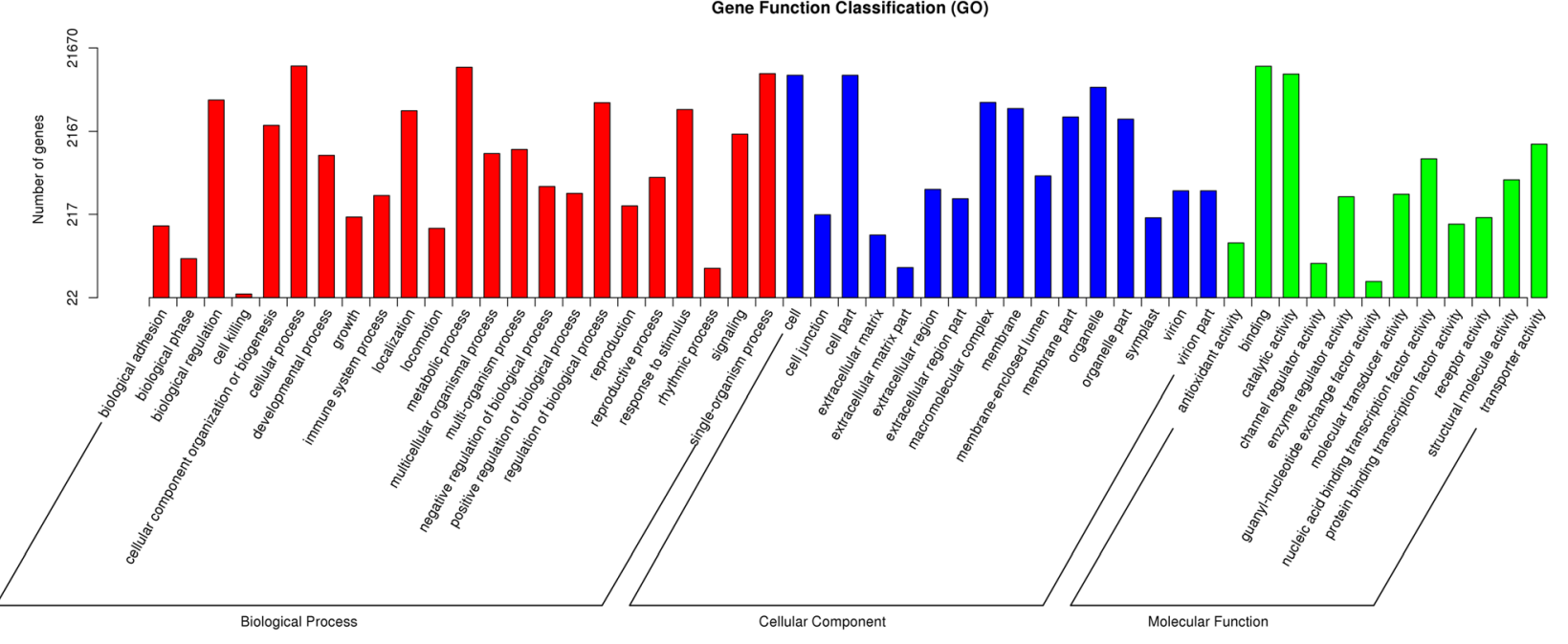

Fig. 3 Gene ontology (GO) analysis of unigenes. The unigenes were summarized in biological process, cellular component and molecular function

mechanism" (6) and "cysteine-type peptidase activity" (10) in the category of MF were significantly enriched between N11 and SD8 samples (Additional file 6-B).

Total 295 genes (165 up- vs 130 down-regulated in the $\mathrm{R}$ plants) were enriched into 113 KEGG pathways (Addditional file 7). The top-five enriched pathways were metabolism of xenobiotics by P450 (8), drug metabolising-P450 (8), retinol metabolism (5), naphthalene degradation (4) and degradation of aromatic compounds (4) (Table 4). In the KEGG pathway analysis, genes involved in "metabolism by P450" changed significantly, suggesting $\mathrm{P} 450$ genes may play a vital role in metabolic resistance to tribenuron-methyl in flixweed.

\section{Differential expressed contigs involved in NTSR}

Among 536 up-regulated contigs in R (N11), no contigs were annotated to the target ALS enzyme. There are 37 contigs (26 up- and 11 down-regulated in R) annotated as metabolism enzymes including 11 P450s, 3 ABC Transporters, 5 GSTs, 16 GTs and 2 PODs. In addition, there are 65 up-regulated contigs in N11 which were not annotated by GO or KEGG enrichment.

Given the important roles of metabolic enzymes in herbicide metabolism and resistance, the contigs that were up-regulated in R samples (N11) and that annotated as metabolic enzymes were selected as the candidate metabolic resistance contigs. Total 26 contigs were selected as candidate genes that may confer tribenuronmethyl resistance. Of which, eight contigs were annotated to P450 families, two annotated to ABC transporter families, two annotated to GST families, thirteen annotated to UGT families and one annotated to POD (Table 5).
qRT-PCR validation of candidate NTSR gene expression The expression of 26 candidate contigs in RNA-seq samples were validated by qRT-PCR. The specificity of each primer pairs designed on the basis of unigene sequences was verified by amplicon sequencing. Two internal control genes (18 s rRNA and ALS) were used in qRT-PCR and the results were normalized as $2^{-\Delta \mathrm{Ct}}$ using the method of Schmittgen and Livak [27]. The results (Table 5) showed that 8 of 26 candidate contigs exhibited significantly higher expression levels in the R (N11) than in $\mathrm{S}$ samples (SD8). These 8 contigs include four P450s, one ABC transporter and three GTs.

The expression patterns of the 8 candidate contigs were also examined in 11 additional plants from the $\mathrm{S}$ (SD8) and 12 from the $\mathrm{R}$ population (N11) respectively. The $\mathrm{S}$ and $\mathrm{R}$ plants used for $\mathrm{qRT}-\mathrm{PCR}$ were grown under the same conditions, and RNAs extracted at the same time as the plants for RNA-Seq. Based on the results of RNA-Seq and qRT-PCR validation (Table 5), 4 out of 26 candidate contigs were expressed, on average, significantly higher in R (N11) than in S (SD8) plants examined. These include three P450s contigs (c1867_g1, c22393_g1, c17043_g1) homology to CYP96A13, CYP86B1 and CYP96A15, respectively, and a contig (c11932_g1) annotated as an $\mathrm{ABC}$ transporter $\mathrm{ABCC} 1$. However, there are variations in individual plants in their expression (data not shown). For example, expressions of contigs c17043_g1 and c22393_g1, which annotated as CYP96A15 and CYP86B1, were up-regulated only in 8 and 5 of 12 individual plants, respectively. Therefore, only contigs c1867_g1 (CYP96A13) and c11932_g1 (ABCC1) were consistently and significantly over-expressed in each $\mathrm{R}$ individuals. 


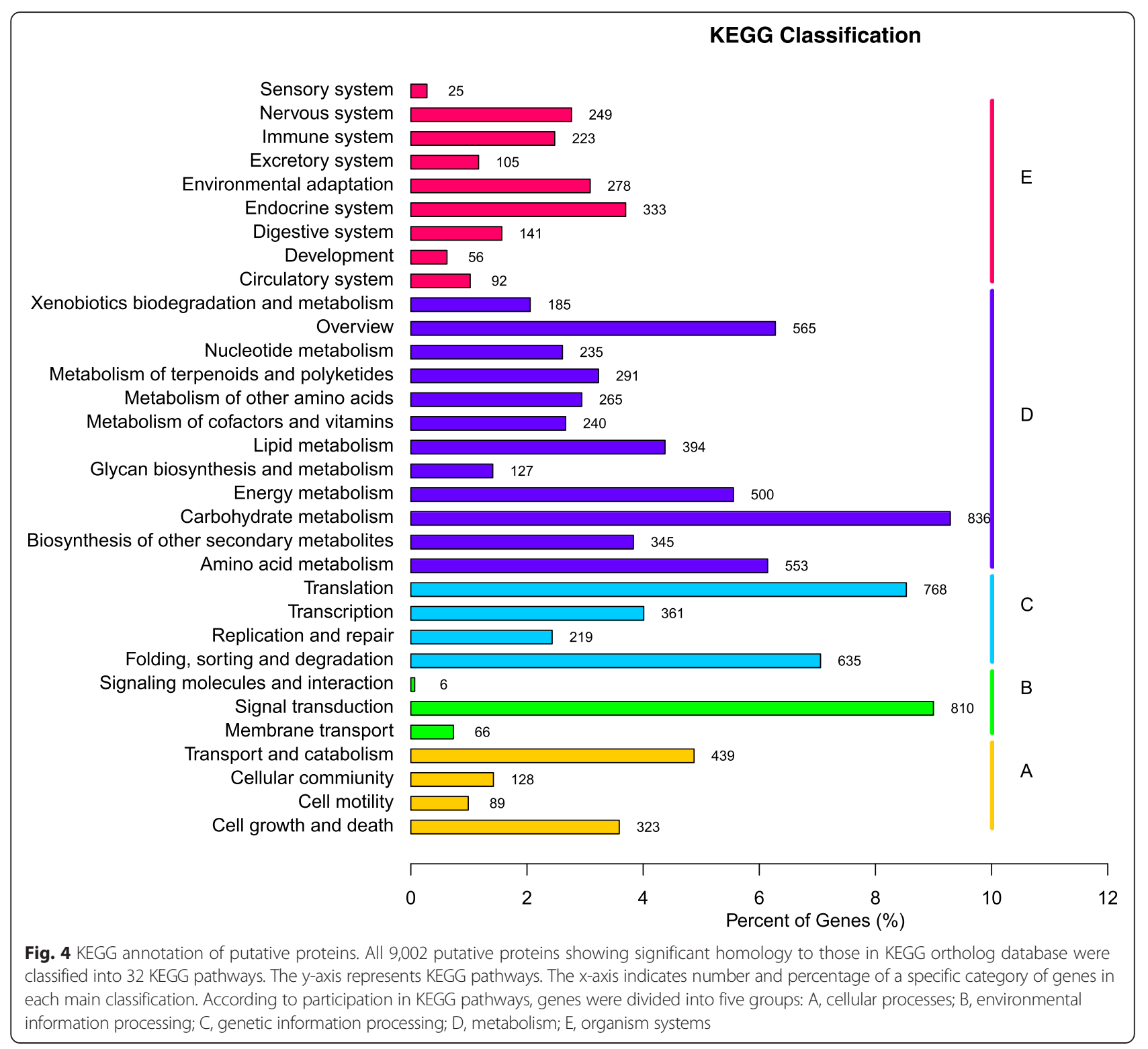

\section{Discussion}

In this study we demonstrate that resistance to tribenuron-methyl in the R population (N11) is due to target-site ALS Pro-197-Thr mutation plus non-targetsite resistance mechanisms because (1) the known Pro197-Thr mutation only provides partial (31-fold) resistance whereas at the whole plant level a more than 100fold resistance was observed (Table 1), and (2) a known P450 inhibitor malathion can largely reverse the resistance (Table 1 and Fig. 1). It has been well established that malathion can inhibit sulfonylurea herbicide metabolism, thus reversing metabolism-based resistance $[1,12]$. Metabolism-based resistance to ALS and ACCaseinhibiting herbicides has long been reported and are increasing in both monocot and dicots weed species $[5,28]$.
However, identification of herbicide-metabolizing and resistance-endowing genes has been slow and only recently a few $\mathrm{P} 450$ genes have been identified in grass weed species [29]. In particular, RNA-Seq has been successfully used to identify genes involved in metabolic resistance to ALS herbicides in two grass weed species L. rigidum [23] and A. myosuroides [24]. However, studies on metabolic herbicide resistance in broadleaf weed species are limited and genes remain unknown. Flixweed is a broad leaf, economically important weed species in China and many populations have evolved high level resistance to the ALS herbicides tribenuron-methyl. Identifying genes involved in NTSR are important for understanding metabolic resistance evolution in this dicot weed species and for development of resistance mitigation strategies. 
Table 4 The top-ten enriched KEGG pathway terms in DEGs between N11 and SD8

\begin{tabular}{|c|c|c|c|c|}
\hline Term $^{a}$ & $I D^{b}$ & Sample number ${ }^{c}$ & Background number $^{d}$ & Corrected $P$-Value \\
\hline Metabolism of xenobiotics by P450 & ko00980 & 8 & 54 & $6.07 \times 10^{-4}$ \\
\hline Drug metabolism - cytochrome P450 & ko00982 & 8 & 54 & $6.07 \times 10^{-4}$ \\
\hline Retinol metabolism & ko00830 & 5 & 18 & $1.45 \times 10^{-3}$ \\
\hline Naphthalene degradation & ko00626 & 4 & 12 & $3.79 \times 10^{-3}$ \\
\hline Degradation of aromatic compounds & ko01220 & 4 & 13 & $3.91 \times 10^{-3}$ \\
\hline Tryptophan metabolism & ko00380 & 6 & 47 & $4.70 \times 10^{-3}$ \\
\hline Tyrosine metabolism & ko00350 & 6 & 47 & $4.70 \times 10^{-3}$ \\
\hline Chloroalkane and chloroalkene degradation & ko00625 & 4 & 17 & $5.82 \times 10^{-3}$ \\
\hline Nitrogen metabolism & ko00910 & 5 & 41 & $1.42 \times 10^{-2}$ \\
\hline Phenylpropanoid biosynthesis & ko00940 & 9 & 148 & $1.85 \times 10^{-2}$ \\
\hline
\end{tabular}

${ }^{a}$ description of KEGG pathway

${ }^{b}$ numbered information of unique pathway in KEGG database

c number of DEGs enriched in this pathway

${ }^{d}$ number of unigenes annotated in this pathway

In this study, 272,121,520 raw reads and 266,750,156 clean reads were generated in flixweed by the Illumina Hiseq 2500 technology, enabling assembling of 84,085 transcripts and 52,898 unigenes (Table 2). The N50 size value of unigenes was 1,569 bp which is comparable or longer than those obtained in recent de novo weed transcriptome assemblies based on Illumina [20, 23, 24]. Because the RNA-seq dataset was obtained from the above-ground material of only four 40 day-old individuals, it may not cover high numbers of total unigenes. However, differential expressed genes in xenobiotic and drug metabolism pathways involving P450 were enriched and well represented (Additional file 7). Although there were only two biological replicates for each population, the gene expression patterns in the four samples exhibited high similarity (Additional file 4). In addition, in this study, we primarily focused on those defensive genes that constitutively differently expressed between the $\mathrm{R}$ and $S$ plants, which we consider to be more effective and efficient in endowing resistance than those genes induced after herbicide treatment.

Among the 536 up-regulated contigs, 26 contigs were annotated to metabolism enzymes including P450, ABC transporter, GST, GT and POD. Of the 26 contigs, eight contigs were validated by qRT-PCR in RNA-seq samples and selected as candidate NTSR genes (Table 5). The eight candidate NTSR genes identified here potentially encoded proteins with homology to four P450s (CYP77A3/ CYP77B1, CYP96A13, CYP86B1, CYP96A15), one ABC transporter (ABCC1) and three GTs (UGT84A1, UGT78D4, UGT91A1).

Further qRT-PCR validation with additional samples from the $\mathrm{R}$ and $\mathrm{S}$ populations identified 4 contigs that expressed on average significantly higher in $\mathrm{R}$ than in $\mathrm{S}$ plants (Table 5). While expression of CYP96A13 and
$\mathrm{ABCC} 1$ was consistently and significantly higher in all individual $\mathrm{R}$ plants than that in all $\mathrm{S}$ plants tested, expression of CYP86B1 and CYP96A15 were not universally higher in all $\mathrm{R}$ individuals. This indicates that CYP96A13 and $\mathrm{ABCC} 1$ are highly associated with tribenuron-methyl resistance, and CYP86B1 and CYP96A15 need further confirmation. Nevertheless, expression variations among individual plants of validated NTSR-related genes had previously been observed in L. rigidum and E. phyllopogon $[22,23,29]$. There are possibilities that individual plants may use slightly different sets of resistance genes to achieve different levels of resistance.

P450s identified so far in ALS tolerant crops or resistant weeds include CYP76B1 in $H$. tuberosus metabolizing phenylurea herbicide [30]; CYP71C6v1 in wheat metabolising sulfonylurea herbicides chlorsulfuron and triasulfuron [31]; CYP76C subfamily in A. thaliana metabolizing monoterpenol [32]; CYP72A31 and CYP81A6 in $O$. sativa or A. thaliana metabolizing bensulfuronmethyl (BSM) [33-35]; CYP81A12 and CYP81A21 in E. phyllopogon metabolizing bensulfuron-methyl (BSM) and penoxsulam (PX) [29]. However, there is lack of reports on involvement of the three candidate P450s (CYP96A13, CYP86B1 and CYP96A15) in herbicide metabolism and resistance. This is likely due to (1) difference in P450s involved in ALS herbicide metabolism in grass and broadleaf species, (2) difference in P450s in metabolizing specific ALS herbicides, and (3) insufficient studies.

Notwithstanding this, these P450s have been reported to play important roles in metabolism of secondary metabolites and catalyze diverse reactions in plants. For example, CYP96A15 was reported to catalyze the hydroxylation of alkane substrate, and involve in biosynthesis of wax secondary alcohols and ketones [36]. CYP86A and 
Table 5 qRT-PCR validations with metabolic resistance candidate genes in flixweed

\begin{tabular}{|c|c|c|c|c|c|}
\hline \multirow[t]{2}{*}{ Gene ID } & \multirow[t]{2}{*}{ Function annotation } & \multirow[t]{2}{*}{ Padj $^{a}$} & \multirow[t]{2}{*}{$\mathrm{FPKM}^{\mathrm{b}}(\mathrm{R} / \mathrm{S})$} & \multicolumn{2}{|c|}{ Fold change: qRT-PCR validation $\left(2^{-\Delta C t}\right)$} \\
\hline & & & & RNA-Seq samples & Addtional samples \\
\hline C29425_g1 & Cyt P450, CYP77B1/77A3 & $1.31 \times 10^{-15}$ & 69.5 & $33.88^{*}$ & 0.57 \\
\hline c1867_g1 & CytP450, CYP96A13 & $2.55 \times 10^{-10}$ & 24.94 & $16.55^{* *}$ & $11.94^{* *}$ \\
\hline c21381_g1 & Cyt P450, CYP71A3 & 4. $25 \times 10^{-3}$ & 22.63 & 4.06 & 1.28 \\
\hline c22393_g1 & Cyt P450, CYP86B1 & $9.35 \times 10^{-11}$ & 20.82 & $4.24^{*}$ & $2.75^{*}$ \\
\hline c17043_g1 & CytP450, CYP96A15 & $2.28 \times 10^{-6}$ & 16.58 & $448.6^{* * *}$ & $24.76^{*}$ \\
\hline c18590_g1 & CytP450, CYP71B14 & $3.9 \times 10^{-2}$ & 12.87 & 1.82 & 1.3 \\
\hline c17358_g1 & CytP450, CYP734A1 & $8.39 \times 10^{-3}$ & 2.91 & 1.95 & 0.85 \\
\hline c25953_g1 & Cyt P450, CYP81F1/81 F3 & $4.33 \times 10^{-2}$ & 2.64 & 2.69 & 0.27 \\
\hline c11932_g1 & $\mathrm{ABC}$ transporter, $\mathrm{ABCC} 1$ & $3.42 \times 10^{-12}$ & $\operatorname{lnf} c$ & $153.43^{*}$ & $9.26^{* * *}$ \\
\hline c31018_g1 & $\mathrm{ABC}$ transporter, $\mathrm{ABCF} 5$ & $1.82 \times 10^{-2}$ & 2.46 & 1.21 & 0.6 \\
\hline c25791_g1 & GST, F11 & $2.46 \times 10^{-3}$ & 3.11 & 1.24 & 1.56 \\
\hline c21822_g2 & GST, U17 & $7.10 \times 10^{-3}$ & 2.87 & 1.46 & 0.86 \\
\hline c19559_g2 & UDP-glycosyltransferase 78D4 & $1.06 \times 10^{-3}$ & 14.87 & 2.42 & 0.94 \\
\hline c33777_g2 & UDP-glycosyltransferase 91A1 & $4.03 \times 10^{-3}$ & 6.52 & 2.36 & 0.74 \\
\hline C24861_g1 & UDP-glycosyltransferase 84A1 & $1.33 \times 10^{-3}$ & 5.76 & $5.33^{*}$ & 0.98 \\
\hline c12944_g1 & UDP-glycosyltransferase 71B1 & $3.02 \times 10^{-6}$ & 5.01 & 2.60 & 0.5 \\
\hline c31999_g1 & UDP-glycosyltransferase 71C2 & $8.92 \times 10^{-5}$ & 4.49 & 1.98 & 0.67 \\
\hline c5029_g1 & UDP-glycosyltransferase 79B6 & $9.54 \times 10^{-5}$ & 4.15 & 3.62 & 0.54 \\
\hline c15368_g1 & UDP-glycosyltransferase 91A1 & $4.68 \times 10^{-3}$ & 3.71 & 2.91 & 0.7 \\
\hline c19559_g1 & UDP-glycosyltransferase 78D4 & $2.38 \times 10^{-2}$ & 3.58 & $4.82^{*}$ & 0.89 \\
\hline c33777_g1 & UDP-glycosyltransferase 91A1 & $1.53 \times 10^{-3}$ & 3.08 & $3.16^{*}$ & 0.53 \\
\hline c29603_g1 & Glycosyl transferases group 1 & $1.64 \times 10^{-2}$ & 2.67 & 1.86 & 0.92 \\
\hline c30538_g1 & Glycosyl transferase family 21 & $3.56 \times 10^{-2}$ & 2.56 & 2.03 & 0.9 \\
\hline c31908_g1 & Glycosyl transferase family 21 & $2.28 \times 10^{-2}$ & 2.51 & 1.46 & 0.78 \\
\hline c29566_g1 & UDP-glycosyltransferase 74D1 & $4.07 \times 10^{-2}$ & 2.51 & 1.65 & 1.18 \\
\hline c28527_g1 & peroxidase activity & $2.89 \times 10^{-2}$ & 4.01 & 2.15 & 1.14 \\
\hline
\end{tabular}

Identification of differentially expressed contigs between tribenuron-methyl susceptible (SD8) and resistant (N11) flixweed populations by RNA-Seq, and the expression levels of the contigs were validated using qRT-PCR with RNA-Seq samples $(n=2)$ and additional samples from resistant N11 ( $n=12$ ) relative to susceptible SD8 $(n=11)$. Fold-change in gene expression $\left(2^{-\Delta C t}\right)$ was calculated relative to the susceptible samples, where $\Delta C_{T}=\left[C_{T}\right.$ target gene- $C_{T}$ mean of two internal control genes]. $P$-value of $<0.05,0.01,0.001$ is indicated by ${ }^{*},{ }^{* *}$, and ${ }^{* * *}$, respectively (from SPSS analysis)

a Padj, adjusted $P$-value, the differentially expressed contigs were fliterred by Padj $<0.05$ from DESeq analysis

${ }^{b}$ FPKM, fragments per kilobase of transcript sequence per millions base pairs sequenced

${ }^{c}$ Inf indicates readcount of SD8 samples $=0$ in RNA-Seq

CYP86B subfamilies catalyze $\omega$-hydroxylation of fatty acids, and involve in the biosynthesis of cutin or suberin in plants $[37,38]$. The hydroxylation and epoxidation catalyzed by P450s are also the important degradation pathways for herbicides $[39,40]$. Hence, the three candidate P450s may play important roles in tribenuron-methyl metabolism and resistance in $D$. sophia. Although correlation of the three P450 candidate genes and tribenuron-methyl resistance was further validated in additionally $11 \mathrm{~S}$ (SD8) and $12 \mathrm{R}$ (N11) samples, more samples are needed to understand the complexity at the population level. For instance, if all the resistant plants employ the same or different sets of P450s in resistance? In cross-pollinated grass weed species (e.g., L. rigidum and A. myosuroides), metabolic herbicide resistance is likely more complex as different individuals may use different sets of candidate P450s $[22,24]$. The next step is functional characterization of these candidate P450s genes using yeast or plant transgenic systems.

In higher plants, ATP-binding cassette (ABC) transporters have been implicated in detoxification of xenobiotic including herbicides [41, 42]. In contrast to the P450s which detoxify herbicides by metabolism, ABC transporters detoxify herbicides and confer herbicide resistance by compartmentation of herbicides and their metabolites [42]. In this current study, the contig 
(c11932_g1) was annotated to ABC transporter ABCC1 and associate with tribenuron-methyl resistance. The vacuolar Arabidopsis multidrug resistance-associated protein 1 (AtABCC1/AtMRP1) was the first plant $\mathrm{ABC}$ transporters to be studied in depth, which transports several glutathione conjugates including the chloroacetanilide herbicide, metolachlor [43]. Although there is no direct evidence on involvement of $\mathrm{ABCC} 1$ in herbicide resistance in weeds, considerable evidence in vitro and in vivo experimental evidence suggests that MRP1 $(\mathrm{ABCC} 1)$ has a role in protecting tissues from toxin induced damage [44]. Two ABCC-type transporters (AtABCC1 and AtABCC2) in A. thaliana were reported to mediate tolerance of arsenic and arsenic-based herbicides [45]. Over expression of AtPgp1, a multi-drug resistant family member, and its garden pea homolog psNTP9 have been shown to confer multi-herbicide resistance in A. thaliana [46]. In addition, the AtMRP4 (homologues to TaMRP1) was reported to be induced by the herbicide safer cloquintocet-mexyl to protect wheat from clodinafop-propargyl injury by transporting herbicide-GST conjugates to vacuoles [47]. Therefore, it is likely that $A B C$ transporter $A B C C 1$ is involved in compartmentation of tribenuron-methyl metabolites in resistant flixweed.

GST and GT are two important herbicide-detoxifying enzymes and play important roles in metabolism and NTSR to herbicides [48-50]. It is noticed that GSTs and GTs in $L$. rigidum were associated with NTSR to the ACCase and ALS herbicide [22, 23]. In this study, two GST and 13 GT contigs were annotated respectively, nevertheless, the average expression levels of these GSTand GT-annotated contigs showed no significant differences between the $\mathrm{R}$ and $\mathrm{S}$ plants in validation experiments with additional plants (Table 5). POD is another metabolic enzyme and plays important roles in plant defense [51]. Whereas, there is few report on its involving herbicide metabolism. In this study, one contig was annotated to POD. Moreover, the expression level of this contig exhibited no significant difference between $\mathrm{S}$ and $\mathrm{R}$ plants in validation experiments (Table 5). Hence, these GSTs, GTs and PODs unlikely play a role in tribenuron-methyl resistance in flixweed.

\section{Conclusions}

A flixweed population (N11) highly resistant to the ALS herbicide tribenuron-methyl was identified, displaying both TSR and NTSR mechanisms. The TSR is due to a known resistance-conferring ALS mutation of Pro-197Thr and the NTSR is likely due to P450-mediated metabolic resistance and $\mathrm{ABC}$ transporter- mediated sequestration of the metabolites. The c1867_g1 (homology to CYP96A13) and c11932_g1 (homology to ABCC1) contigs are potential NTSR genes or markers, for metabolic resistance to tribenuron-methyl in flixweed. Functional characterization of the identified P450 gene (CYP96A13) and the transporter gene $(\mathrm{ABCC} 1)$ using transgenic plants is therefore warranted. This study will greatly extend our understanding the herbicide resistance mechanisms, and may identify the genes involving in herbicide metabolism.

\section{Methods}

\section{Plants materials}

Mature seeds of the susceptible (S) flixweed population (SD8) were collected from roadsides at Linyi in

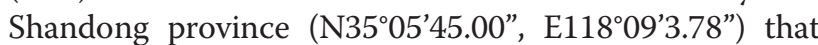
had never been treated with herbicides. Seeds of the resistant (R) flixweed population (N11), were harvested randomly from winter wheat fields at Baoding of Hebei province (N38 36'32.80", E115 $01^{\prime} 52.50^{\prime \prime}$ ) in 2013.

Flixweed seeds were polished by abrasive paper for $30 \mathrm{~s}$, and then immersed in $0.3 \%$ gibberellin solution for $30 \mathrm{~min}$. After rinsing thoroughly with distilled water, they were germinated in Petri dishes for $72 \mathrm{~h}$. Germinating seedlings were transplanted into 9-cm diameter plastic pots containing moist loam soil, and then kept in a climate chamber at $20^{\circ} \mathrm{C} / 15{ }^{\circ} \mathrm{C}$ (day/night), $14 \mathrm{~h}$ photoperiod with light intensity of 20,000 Lux [16].

\section{Tribenuron-methyl dose response in the absence and presence of the cytochrome P450 inhibitor malathion} Whole-plant response experiments were conducted to determine the sensitivities of SD8 and N11 populations to tribenuron-methyl in the absence and presence of malathion. Malathion at the rate of $720 \mathrm{~g}$ a.i.ha ${ }^{-1}$ has no visual effects on flixweed seedling growth, and therefore, was used to treat the plants $30 \mathrm{~min}$ prior to tribenuron-methyl treatment. Tribenuron-methyl (diluted in water containing $0.3 \%$ Tween-80) rates of $5.72 \times 10^{-4}, 2.29 \times 10^{-3}, 9.16 \times 10^{-3}, 3.66 \times 10^{-2}, 0.15$, $0.59,2.34 \mathrm{~g}$ a.i.ha ${ }^{-1}$ were used to treat the $\mathrm{S}$ plants, and $3.66 \times 10^{-2}, 0.15,0.59,2.34,9.38,18.75,37.50,75$ g a.i.ha ${ }^{-1}$ for the R plants. Control plants were treated with $0.3 \%$ Tween-80 solution.

Tribenuron-methyl was applied using a moving-boom cabinet sprayer delivering $600 \mathrm{~L} \mathrm{ha}^{-1}$ water at a pressure of $0.4 \mathrm{MPa}$ by a flat fan nozzle positioned at $54 \mathrm{~cm}$ above the foliage. Treated plants were returned to the climate chamber. The aboveground shoots were harvested 21 days after treatment and the dry weight determined. The experiment was conducted with three replicates per herbicide dose and repeated once.

\section{In vitro ALS activity}

The 5-6 leaf stage seedlings (40 days after transplant) were used for in vitro ALS activity assay. The ALS extraction and activity assay were conducted according to 
the methods described by $\mathrm{Yu}$ et al. [52] and Deng et al. [17]. ALS activity was determined colorimetrically $(520 \mathrm{~nm})$ with microplate photometer (Thermo Fisher) by measuring acetoin production. Each assay was conducted with three replicates and repeated two times with independent enzyme extracts. Technical grade tribenuron-methyl was used in the reaction mixture with the final concentrations of $1.0 \times 10^{-5}, 1.0 \times 10^{-4}, 1.0 \times 10^{-3}$, $1.0 \times 10^{-2}, 0.1,1.0,10,1.0 \times 10^{2}, 5.0 \times 10^{2}$ and $1.0 \times 10^{3} \mu \mathrm{M}$, respectively.

\section{Statistical analyses}

Data obtained from tribenuron-methyl dose-response and in vitro ALS activity assay were converted into percentage of the control and subjected to the non-linear regression analysis. The herbicide rates causing $50 \%$ plant growth reduction $\left(\mathrm{GR}_{50}\right)$ and herbicide concentration causing $50 \%$ inhibition of ALS activity $\left(\mathrm{I}_{50}\right)$ were evaluated using the four-parameter log-logistic Eq. proposed by Seefeldt et al. [53].

$$
y=C+(D-C) /\left[1+\left(x / \mathrm{I}_{50} \text { or } \mathrm{GR}_{50}\right)^{b}\right]
$$

Where $C$ is the lower limit, $D$ is the upper limit, $b$ is the slope at the $I_{50}$ or $G_{50}$. The resistance factor (RF) was calculated by the $\mathrm{GR}_{50}$ or $\mathrm{I}_{50}$ of the $\mathrm{R}$ population divided by that of the $S$ population to estimate the resistance levels.

\section{ALS gene sequencing}

Genomic DNA was extracted from shoot tissue of the four-leaf stage individual plants using the DNA extraction kit (Tiangen, Beijing, China). Primers (forward: $5^{\prime}-$ TCTATCTCTCGCTCCTCTCC-3'; reverse: 5'-GCGTC TGAAGTAAATGAAAAAC- $3^{\prime}$ ) were designed based on the ALS sequences of flixweed (FJ715633). The $25 \mu \mathrm{L}$ polymerase chain reaction (PCR) mixture consisted of $100 \mathrm{ng}$ of genomic DNA, $0.5 \mu \mathrm{L}(25 \mu \mathrm{M})$ of each primer and $12.5 \mu \mathrm{L}$ of $2 \times$ Taq PCR Master Mix and $10.5 \mu \mathrm{L}$ of $\mathrm{dd}_{2} \mathrm{O}$ (Tiangen, Beijing, China). PCR was run with the following program: denaturation at $94{ }^{\circ} \mathrm{C}$ for $3 \mathrm{~min}, 35 \mathrm{cy}$ cles of $94{ }^{\circ} \mathrm{C}$ for $45 \mathrm{~s}, 58{ }^{\circ} \mathrm{C}$ for $45 \mathrm{~s}$ and $72{ }^{\circ} \mathrm{C}$ for $2 \mathrm{~min}$ $30 \mathrm{~s}$, followed finally by an extension step of $10 \mathrm{~min}$ at $72{ }^{\circ} \mathrm{C}$. PCR product was purified from agarose gel with TIAN gel Midi Purification Kit (Tiangen, Beijing, China).

The purified PCR products were cloned into the pGM-T vector and transformed into TOP10 Chemically Competent Cells. Escherichia coli clones containing the insert were sequenced directly with the universal primers T7 and SP6 commercially (Sangon, Shanghai, China). Eight clones of each plant $(n=10)$ were sequenced respectively for S (SD8) and R (N11) populations. ALS sequences of $\mathrm{S}$ and $\mathrm{R}$ plants were compared with the published susceptible sequence (BJ25) (EMBL/
Genbank accession JQ868736) to determine the potential resistance mutations.

\section{RNA extraction and quality determination for RNA-Seq}

Total RNA was extracted from leaves of two individual $\mathrm{R}$ and $\mathrm{S}$ plants, respectively, using the RNApre Pure Plant Kit (Tiangen, Beijing, China). RNA purity was checked using the NanoPhotometer spectrophotometer (IMPLEN, CA, USA), and RNA concentration were determined using the Qubit $^{\circ}$ RNA Assay Kit (Qubit ${ }^{\circ} 2.0$ Flurometer, Life Technologies, CA, USA). RNA integrity was assessed using the RNA Nano 6000 Assay Kit (Agilent Bioanalyzer 2100 system, Agilent Technologies, USA). The best qualified RNA samples were chosen for cDNA library preparation.

\section{cDNA library construction and sequencing}

A total amount of $3 \mu \mathrm{g}$ RNA per sample was used as input material for the RNA sample preparations. Sequencing libraries were generated using the NEBNext ${ }^{\circ}$ Ultra $^{\text {Tw }}$ RNA Library Prep Kit for Illumina ${ }^{\circ}$ (NEB, USA) following manufacturer's recommendations, and mRNA purified from total RNA using poly-T oligo-linked magnetic beads. Fragmentation was carried out using divalent cations under elevated temperature in NEBNext first strand synthesis reaction buffer (5X). First strand cDNA was synthesized using random hexamer primer and M-MuLV reverse transcriptase (RNaseH). Second strand cDNA synthesis was subsequently performed using DNA polymerase I and RNase H. Remaining overhangs were converted into blunt ends via exonuclease/polymerase activities. After adenylation of 3' ends of DNA fragments, NEBNext adaptors with hairpin loop structure were ligated to prepare for hybridization. In order to select cDNA fragments of preferentially $150 \sim 200 \mathrm{bp}$ in length, the library fragments were purified with the AMPure XP system (Beckman Coulter, Beverly, USA). Then $3 \mu \mathrm{L}$ USER Enzyme (NEB, USA) was used with size-selected, adaptor-ligated cDNA at $37{ }^{\circ} \mathrm{C}$ for $15 \mathrm{~min}$ followed by $5 \mathrm{~min}$ at $95{ }^{\circ} \mathrm{C}$ before PCR. Then PCR was performed with Phusion HighFidelity DNA polymerase, universal PCR primers and index (X) primers. Finally, PCR products were purified (AMPure XP system) and library quality assessed on the Agilent Bioanalyzer 2100 system. The clustering of the index-coded samples was performed on a cBot Cluster Generation System using the TruSeq PE Cluster Kit v3cBot-HS (Illumina). After cluster generation, four libraries (N11_4, N11_5, SD8_3 and SD8_4) preparations were sequenced on the Illumina Hiseq 2500 platform and 125 bp paired-end reads were generated.

Transcriptome assembly and gene functional annotation Clean reads were obtained by removing reads containing adapters or ploy- $\mathrm{N}$ and low quality reads from raw data 
by in-houseperl scripts. At the same time, Q20, Q30, $\mathrm{GC}$-content and sequence duplication level of the clean data were calculated. All the downstream analyses were based on clean data with high quality. Transcriptome assembly was accomplished using Trinity [54] with min_kmer_cov set to 2 by default and all other parameters set default. Gene function was annotated based on the plant protein dataset of $\mathrm{Nr}, \mathrm{Nt}$, Swiss-Prot database and KOG/COG, respectively, with a significance threshold of $E$-value $\leq 10^{-5}$. The GO terms for functional categorization were analyzed using Blast2go software with $E$-value $\leq 10^{-6}$. The pathway assignments were carried out by sequence searches against the KEGG database, using KAAS software with an $E$-value threshold $\leq 10^{-10}$.

\section{Differential gene expression analysis}

Gene expression levels were estimated by RSEM for each sample [55]. Clean reads were mapped back onto the assembled transcriptome, and read count for each gene was obtained from the mapping results and normalized to FPKM (expected number of fragments per kilobase of transcript sequence per millions base pairs sequenced). Differential expression analysis of two groups was performed using the DESeq $\mathrm{R}$ package (1.10.1). The resulting $P$-values were adjusted using the Benjamini and Hochberg's approach for controlling the false discovery rate. Genes with an adjusted $P$-value $<0.05$ found by DESeq were assigned as differentially expressed.

Differentially expressed genes (DEGs) were analyzed by GO and KEGG enrichment analysis. GO enrichment analysis was implemented by the GOseq $\mathrm{R}$ packages based Wallenius non-central hyper-geometric distribution [56]. The statistical enrichment of DEGs in KEGG pathways were tested by KOBAS [57] software.

\section{qRT-PCR validation of RNA-Seq expression patterns}

Primers to amplify candidate contigs were designed based on sequence of the identified unigenes and listed in Additional file 8. Amplification specificity was checked by comparing the sequences of the amplicon with that of unigene. The $18 \mathrm{~s}$ rRNA and ALS were used as internal control genes in qRT-PCR.

Total RNA was extracted and purified using the RNApre Pure Plant Kit (Tiangen, Beijing, China). $1 \mu \mathrm{g}$ of RNA was used for first-stand cDNA synthesis using the FastQuant RT Kit (Tiangen, Beijing, China). qRTPCR was conducted in 96-well plates on the ABI 7500 real time PCR system (ABI Life Technologies) using SuperReal PreMix Plus (SYBR Green) (Tiangen, Beijing, China). Reactions were conducted in a $20 \mu \mathrm{L}$ volume with four replicates for each cDNA sample. Each reaction mixture included $10 \mu \mathrm{L} 2 \times$ SuperReal PreMix Plus, $1 \mu \mathrm{L}$ diluted $\mathrm{cDNA}, 0.6 \mu \mathrm{L}$ primers, $0.4 \mu \mathrm{L} 50 \times \mathrm{ROX}$ reference dye, and 7.4 $\mu \mathrm{L}$ RNase-free $\mathrm{ddH}_{2} \mathrm{O}$. qRT-PCR programs consisted of $15 \mathrm{~min}$ incubation at $95{ }^{\circ} \mathrm{C}, 40 \mathrm{cy}$ cles of $95{ }^{\circ} \mathrm{C}$ for $10 \mathrm{~s}, 56{ }^{\circ} \mathrm{C}$ for $20 \mathrm{~s}$ and $72{ }^{\circ} \mathrm{C}$ for $32 \mathrm{~s}$. At the end of the amplification cycle, a melting analysis was carried out to verify the absence of non-specific amplification. Similar amplification efficacy of the target and internal control genes (86.0 \%-99.8 \%) were observed. Fold-change in gene expression (as $2^{-\Delta \mathrm{Ct}}$ ) was calculated by the comparative $\mathrm{C}_{\mathrm{T}}$ method [27], relative to the susceptible samples, where ${ }^{\Delta} \mathrm{C}_{\mathrm{T}}=\left[\mathrm{C}_{\mathrm{T}}\right.$ target gene$\mathrm{C}_{\mathrm{T}}$ mean of two internal control genes].

\section{Additional files}

Additional file 1: Assessment of assembly quality for resistant (N11) and susceptible (SD8) flixweed populations. (PDF 51 kb)

Additional file 2: The length distribution of the transcripts and unigenes. The length distribution of the transcripts (red) and unigenes (blue). (PDF $4 \mathrm{~kb}$ )

Additional file 3: Species that flixweed unigenes were annotated by BLAST search. (PDF 6 kb)

Additional file 4: Pearson correlation (R) between susceptible (SD8) and resistant (N11) samples. (PDF $5 \mathrm{~kb}$ )

Additional file 5: Volcano plot of differentially expression genes (DEGs) between resistant (N11) and susceptible (SD8) populations. Red spots represent up-regulated DEGs and green spots indicate down-regulated DEGs. Those shown in blue are unigenes that did not show obvious changes. (PDF $146 \mathrm{~kb}$ )

Additional file 6: Histogram of GO classification of the DEGs. The results are summarized in three main GO categories: biological process, cellular component and molecular function. The $x$-axis indicates the subcategories, and the $y$-axis indicates the numbers related to the total number of $\mathrm{GO}$ terms present; the DEGs numbers that are assigned the same GO terms are indicated at the top of the bars. (PDF $282 \mathrm{~kb}$ )

Additional file 7: The scatter plots of top 20 pathways by KEGG enrichment. The $x$-axis indicates the Rich factor of each pathway, and the $y$-axis indicates the name for each pathway. Color scale indicates the $q$-value. The size of the spots indicates the numbers of the DEGs in each pathway. (PDF $6 \mathrm{~kb}$ )

Additional file 8: Primer information for qRT-PCR validation. (XLSX $14 \mathrm{~kb}$ )

\section{Abbreviations}

ACCase, acetyl-CoA carboxylase; ALS, acetolactate synthase; BP, biologic process; CC, cellular component; DEGs, differentially expressed genes; EPSPS, 5-enolpyruvlshikimate-3-phosphate synthase; FPKM, expected number of fragments per kilobase of transcript sequence per millions base pairs sequenced; GO, gene ontology; GST, glutathione S-transferase; GT, glycosyltransferase; HPPD, 4-hydroxyphenpyruvate dioxygenase; KEGG, Kyoto encyclopedia of genes and genomes; KOG/COG, clusters of orthologous groups of proteins; MF, molecular function; NCBI, National Center for Biotecnology Information; Nr, NCBI non-redundant protein sequences database; Nt, NCBI non-redundant nucleotide sequences database; NTSR, non-target-site based resistance; Pfam, protein family; POD, peroxidase; PPO, protoporphyrinogen IX oxidase; RF, resistance factor; RNA-Seq, highthroughput RNA-sequencing; SRA, sequence read archive; TSR: targetbased resistance

\section{Acknowledgements}

This work was supported by Special Fund for Agro-scientific Research in the Public Interest (201303031).

\section{Availability of data and materials}

The datasets supporting the conclusions of this article are included within the article and its additional files. The raw Illumina sequence reads have 
been deposited in the NCBI Sequence Read Archive (SRA) database with accession number SRP071775 including SRX1631774 for SD8 (S) and SRX1631775 for N11 (R)

\section{Authors' contributions}

This study was designed and performed by QianY and MQZ. QianY analyzed the sequencing data, performed GRT-PCR validations and wrote the manuscript. The collection of plant materials, dose-response experiments and ALS activity assays were conducted by WD. QinY, XFL and LYB provided helpful suggestion in data analysis and manuscript revision. All authors read and approved the final manuscript.

\section{Competing interests}

The authors declare that they have no competing interests.

\section{Ethics approval and consent to participate}

This research did not involve any human subjects, human material, of human data. D. sophia in current research did not belong to the endangered or protected species.

\section{Author details}

Department of Applied Chemistry, College of Science, China Agricultural University, Beijing 100193, China. ${ }^{2}$ Australian Herbicide Resistance Initiative, School of Plant Biology, University of Western Australia, Crawley, WA 6009, Australia. ${ }^{3}$ Hunan Academy of Agricultural Science, Changsha 410125, China.

Received: 6 April 2016 Accepted: 7 July 2016

Published online: 05 August 2016

\section{References}

1. Powles SB, Yu Q. Evolution in action: Plants resistant to herbicides. Annu Rev Plant Biol. 2010;61:317-47.

2. Dayan FE, Owens DK, Tranel PJ, Preston C, Duke SO. Evolution of resistance to phytoene desaturase and protoporphyrinogen oxidase inhibitors - state of knowledge. Pest Manag Sci. 2014;70:1358-66.

3. Kaundun SS. Resistance to acetyl-CoA carboxylase-inhibiting herbicides. Pest Manag Sci. 2014;70:1405-17.

4. Sammons RD, Gaines TA. Glyphosate resistance: state of knowledge. Pest Manag Sci. 2014;70:1367-77.

5. $\quad \mathrm{Yu}$ Q, Powles SB. Resistance to AHAS inhibitor herbicides: current understanding. Pest Manag Sci. 2014;70:1340-50

6. Heap I. The international survey of herbicide resistant weeds. 2016. http://www.weedscience.com. Accessed 4 Aug 2016

7. Tranel P, Wright TR. Resistance of weeds to ALS-inhibiting herbicides: what have we learned? Weed Sci. 2002:50:700-12.

8. Délye C. Unravelling the genetic bases of non-target-site-based resistance (NTSR) to herbicides: a major challenge for weed science in the forthcoming decade. Pest Manag Sci. 2013;69:176-87.

9. Siminszky B. Plant cytochrome P450-mediated herbicide metabolism. Phytochem Rev. 2006;5:445-58

10. Yuan JS, Tranel PJ, Stewart CN. Non-target-site herbicide resistance: a family business. Trends Plant Sci. 2007;12:6-13.

11. Yu Q, Han H, Cawthray GR, Wang SF, Powles SB. Enhanced rates of herbicide metabolism in low herbicide-dose selected resistant Lolium rigidum. Plant Cell Environ. 2013;36:818-27.

12. Yu Q, Powles SB. Metabolism-based herbicide resistance and crossresistance in crop weeds: a threat to herbicide sustainability and global crop production. Plant Physiol. 2015;166:1106-18.

13. Délye C, Jasieniuk M, Corre VL. Deciphering the evolution of herbicide resistance in weeds. Trends Genet. 2013;29:649-58.

14. Cui HL, Zhang CX, Zhang HJ, Liu X, Wang GQ, Huang HJ, Wei SH. Confirmation of flixweed (Descurainia sophia) resistance to tribenuron in China. Weed Sci. 2008:56:775-9.

15. Cui HL, Zhang CX, Wei SH, Zhang HJ, Li XJ, Zhang YQ, Wang GQ. Acetolactate synthase gene proline (197) mutations confer tribenuronmethyl resistance in flixweed (Descurainia sophia) populations from China. Weed Sci. 2011:59:376-9.

16. Han XJ, Dong Y, Sun XN, Li XF, Zheng MQ. Molecular basis of resistance to tribenuron-methyl in Descurainia Sophia (L.) populations from China. Pestic Biochem Physiol. 2012;104:77-81.
17. Deng W, Cao Y, Yang Q, Liu MJ, Mei Y, Zheng MQ. Different crossresistance patterns to AHAS herbicides of two tribenuron-methyl resistant flixweed (Descurainia sophia L.) biotypes in China. Pestic Biochem Physiol. 2014;112:26-32.

18. Deng W, Liu MJ, Yang Q, Mei Y, Li XF, Zheng MQ. Tribenuron-methyl resistance and mutation diversity of Pro197 in flixweed (Descurainia Sophia L) accessions from China. Pestic Biochem Physiol. 2015;117:68-74.

19. Xu X, Liu G, Chen S, Li B, Liu X, Wang X, Fan C, Wang G, Ni H. Mutation at residue 376 of ALS confers tribenuron-methyl resistance in flixweed (Descurainia sophia) populations from Hebei province, China. Pestic Biochem Physiol. 2015;125:62-8.

20. An J, Shen X, Ma Q, Yang C, Liu S, Chen Y. Transcriptome Profiling to Discover Putative Genes Associated with Paraquat Resistance in Goosegrass (Eleusine indica L.). PLoS One. 2014;9:e99940.

21. Yang X, Yu XY, Li YF. De novo Assembly and Characterization of the Barnyardgrass (Echinochloa crus-galli) Transcriptome Using Next-Generation Pyrosequencing. PLoS One. 2013;8:e69168.

22. Gaines TA, Lorentz L, Figge A, Herrmann J, Maiwald F, Ott MC, et al. RNA-Seq transcriptome analysis to identify genes involved in metabolism-based diclofop resistance in Lolium rigidum. Plant J. 2014;78:265-76.

23. Duhoux A, Carrère S, Gouzy J, Bonin L, Délye C. RNA-Seq analsis of rye-grass transcriptomic response to an herbicide inhibiting acetolactate-synthase identifies transcripts linked to non-target-site-based resistance. Plant Mol Biol. 2015;87:473-87.

24. Gardin JAC, Gouzy J, Carrère S, Délye C. ALOMYbase, a resource to investigate non-target-site-based resistance to herbicides inhibiting acetolactate-synthase (ALS) in the major grass weed Alopecurus myosuroides (black-grass). BMC Genomics. 2015;16:590-611.

25. Christopher JT, Preston C, Powles SB. Malathion antagonizes metabolismbased chlorsulfuron resistance in Lolium rigidum. Pestic Biochem Physiol. 1994:49:172-82.

26. Anders $\mathrm{S}, \mathrm{Huber}$ W. Differential expression analysis for sequence count data. Genome Biol. 2010:11:R106.

27. Schmittgen TD, Livak KJ. Analyzing real-time PCR data by the comparative CT method. Nat Protoc. 2008:3:1101-8.

28. Beckie HJ, Tardif FJ. Herbicide cross resistance in weeds. Crop Prot. 2012:35:15-28.

29. Iwakami S, Endo M, Saika H, Okuno J, Nakamura N, Yokoyama M, et al. Cytochrome P450 CYP81A12 and CYP81A21 are associated with resistance to two acetolactate synthase inhibitors in Echinochloa phyllopogon. Plant Physiol. 2014;165:618-29.

30. Didierjean L, Gondet L, Perkins R, Lau SMC, Schaller H, O'Keefe DP, Werck-Reichhart D. Engineering herbicide metabolism in tobacco and Arabidopsis with CYP76B1, a cytochrome P450 enzyme from Jerusalem artichoke. Plant Physiol. 2002;130:179-89.

31. Xiang W, Wang X, Ren T, Ci S. Expression of a wheat cytochrome P450 monooxygenase CDNA in yeast catalyzes the metabolism of sulfonylurea herbicides. Pestic Biochem Physiol. 2006:85:1-6.

32. Höfer R, Boachon B, Renault H, Gavira C, Miesch L, Iglesias J, et al. Dual function of the cytochrome P450 CYP76 family from Arabidopsis thaliana in the metabolism of monoterpenols and phenylurea herbicides. Plant Physiol. 2014:166:1149-61.

33. Saika H, Horita J, Taguchi-Shiobara F, Nonaka S, Nishizawa-Yokoi A, Iwakami S, et al. A novel rice cytochrome P450 gene, CYP72A31, confers tolerance to acetolactate synthase-inhibiting herbicides in rice and Arabidopsis. Plant Physiol. 2014;166:1232-40.

34. Liu C, Liu S, Wang F, Wang Y, Liu K. Expression of a rice CYP81A6 gene confers tolerance to bentazon and sulfonylurea herbicides in both Arabidopsis and tobacco. Plant Cell Tiss Org. 2012;109:419-28.

35. Pan G, Zhang X, Liu K, Zhang J, Wu X, Zhu J, Tu J. Map based cloning of a novel rice cytochrome P450 gene CYP81A6 that confers resistance to two different classes of herbicides. Plant Mol Biol. 2006;61:933-43.

36. Greer S, Wen M, Bird D, Wu X, Samuels L, Kunst L, Jetter R. The Cytochrome P450 enzyme CYP96A15 is the midchain alkane hydroxylase responsible for formation of secondary alcohols and ketones in stem cuticular wax of Arabidopsis. Plant Physiol. 2007;145:653-67.

37. Pinot F, Beisson F. Cytochrome P450 metabolizing fatty acids in plants: characterization and physiological roles. FEBS J. 2011;278:195-205.

38. Compagnon V, Diehl P, Benveniste I, Meyer D, Schaller H, Schreiber L, Franke R, Pinot F. CYP86B1 is required for very long chain omega- 
hydroxyacid and alpha, omega-dicarboxylic acid synthesis in root and seed suberin polyester. Plant Physiol. 2009;150:1831-43.

39. Werck-Reichhart D, Hehn A, Didierjean L. Cytochromes P450 for engineering herbicide tolerance. Trends Plant Sci. 2000;5:116-23.

40. Inui $\mathrm{H}$, Ohkawa $\mathrm{H}$. Herbicide resistance in transgenic plants with mammalian monooxygenase genes. Pest Manag Sci. 2005;61:286-91.

41. Conte SS, Lloyd AM. Exploring multiple drug and herbicide resistance in plants-spotlight on transporter proteins. Plant Sci. 2011;180:196-203.

42. Rea PA. Plant ATP-binding cassette transporters. Annl Rev Plant Biol. 2007;58:347-75.

43. Lu YP, Li ZS, Rea PA. AtMRP1 gene of Arabidopsis encodes a glutathione S-conjugate pump: Isolation and functional definition of a plant ATPbinding cassette transporter gene. Proc Natl Acad Sci U S A. 1997;94:8243-8.

44. Leslie EM, Deeley RG, Cole SPC. Toxicological relevance of the multidrug resistance protein 1, MRP1 (ABCC1) and related transporters. Toxicology. 2001;167:3-23

45. Song WY, Park J, Mendoza-Cózatl DG, Suter-Grotemeyer M, Shim D, Hörtensteiner S. Arsenic tolerance in Arabidopsis is mediated by two ABCC-type phytochelatin transporters. Proc Natl Acad Sci U S A. 2010;107:21187-92.

46. Windsor B, Roux SJ, Lloyd A. Multiherbicide tolerance conferred by AtPgp 1 and apyrase overexpression in Arabidopsis thaliana. Nat Biotechnol. 2003;21:428-33.

47. Theodoulou FL, Clark IM, He XL, Pallett KE, Cole DJ, Hallahan DL. Coinduction of glutathione-S-transferases and multidrug resistance associated protein by xenobiotics in wheat. Pest Manag Sci. 2003;59:202-14.

48. Cummins I, Wortley DJ, Sabbadin F, He ZS, Coxon CR, Straker HE, et al. Key role for a glutathione transferase in multiple-herbicide resistance in grass weeds. Proc Natl Acad Sci U S A. 2013;1 10:5812-7.

49. Lairson LL, Henrissat B, Davies GJ, Withers SG. Glycosyltransferases: structures, functions, and mechanisms. Annu Rev Biochem. 2008;77:521-55.

50. Lim CE, Ahn JH, Lim J. Molecular Genetic Analysis of Tandemly Located Glycosyltransferase Genes, UGT73B1, UGT73B2, and UGT73B3, in Arabidopsis thaliana. J Plant Biol. 2006;49:309-14.

51. Passardi F, Cosio C, Penel C, Dunand C. Peroxidases have more functions than a Swiss army knife. Plant Cell Rep. 2005;24:255-65.

52. Yu Q, Han H, Vila-Aiub MM, Powles SB. AHAS herbicide resistance endowing mutations: effect on AHAS functionality and plant growth. J Exp Bot. 2010;16:3925-34.

53. Seefeldt SS, Jensen JE, Fuerst EP. Log-logistic analysis of herbicides doseresponse relationships. Weed Technol. 1995;9:218-27.

54. Grabherr MG, Haas BJ, Yassour M, Levin JZ, Thompson DA, Amit I, et al. Fulllength transcriptome assembly from RNA-Seq data without a reference genome. Nat Biotechnol. 2011;20:644-52.

55. Li B, Dewey CN. RSEM: accurate transcript quantification from RNA-Seq data with or without a reference genome. BMC Bioinformatics. 2011;12:323.

56. Young MD, Wakefield MJ, Smyth GK, Oshlack A. Gene ontology analysis for RNA-seq: accounting for selection bias. Genome Biol. 2010;11:R14.

57. Mao X, Cai T, Olyarchuk JG, Wei L. Automated genome annotation and pathway identification using the KEGG Orthology (KO) as a controlled vocabulary. Bioinformatics. 2005;21:3787-93.

\section{Submit your next manuscript to BioMed Central and we will help you at every step:}

- We accept pre-submission inquiries

- Our selector tool helps you to find the most relevant journal

- We provide round the clock customer support

- Convenient online submission

- Thorough peer review

- Inclusion in PubMed and all major indexing services

- Maximum visibility for your research

Submit your manuscript at www.biomedcentral.com/submit

C Biomed Central 